\title{
Impact of preadmission treatment with calcium channel blockers or beta blockers on short-term mortality after stroke: a nationwide cohort study
}

\author{
Jens Sundbø|l ${ }^{1,2^{*}}$, Morten Schmidt ${ }^{1,2}$, Erzsébet Horváth-Puhó ${ }^{1}$, Christian F Christiansen ${ }^{1}$, Lars Pedersen ${ }^{1}$,
} Hans Erik Bøtker ${ }^{2}$ and Henrik T Sørensen ${ }^{1}$

\begin{abstract}
Background: The prognostic impact of preadmission use of calcium channel blockers (CCBs) and beta blockers (BBs) on stroke mortality remains unclear. We aimed to examine whether preadmission use of CCBs or BBs was associated with improved short-term mortality following ischemic stroke, intracerebral hemorrhage (ICH), or subarachnoid hemorrhage (SAH).
\end{abstract}

Methods: We conducted a nationwide population-based cohort study using Danish medical registries. We identified all patients with a first-time inpatient diagnosis of stroke between 2004 and 2012 and their comorbidities. We defined $\mathrm{CCB} / \mathrm{BB}$ use as current use, former use, or non-use. Current use was further classified as new or long-term use. We used Cox regression modeling to compute 30-day mortality rate ratios (MRRs) with 95\% confidence intervals (Cls), controlling for potential confounders.

Results: We identified 100,043 patients with a first-time stroke. Of these, 83,736 (83.7\%) patients had ischemic stroke, $11,779(11.8 \%)$ had ICH, and 4,528 (4.5\%) had SAH. Comparing current users of CCBs or BBs with non-users, we found no association with mortality for ischemic stroke [adjusted 30-day MRR $=0.99$ (95\% Cl: 0.94-1.05) for CCBs and 1.01 (95\% Cl: 0.96-1.07) for BBs], ICH [adjusted 30-day MRR = 1.05 (95\% Cl: 0.95-1.16) for CCBs and 0.95 (95\% Cl: 0.87-1.04) for BBs], or SAH [adjusted 30-day MRR $=1.05$ (95\% Cl: 0.85-1.29) for CCBs and 0.89 (95\% Cl: 0.72-1.11) for BBs]. Former use of CCBs or BBs was not associated with mortality.

Conclusions: Preadmission use of CCBs or BBs was not associated with 30-day mortality following ischemic stroke, ICH, or SAH.

Keywords: Beta-blocker, Calcium channel blocker, Stroke, Ischemic stroke, Hemorrhagic stroke, Mortality

\section{Background}

Stroke is one of the most disabling neurological diseases [1]. It is expected to remain the second leading cause of death worldwide, exceeded only by myocardial infarction [1-3]. From 1999 to 2009, the annual incidence of firsttime stroke was approximately 600,000 cases in the United States [4]. Thirty-day mortality is approximately $11 \%$ for ischemic stroke [5], 34\% for intracerebral hemorrhage (ICH) [5], and $29 \%$ for subarachnoid hemorrhage (SAH) [6].

\footnotetext{
* Correspondence: jens.sundboll@clin.au.dk

'Department of Clinical Epidemiology, Aarhus University Hospital, Olof Palmes Allé 43-45, Aarhus N DK-8200, Denmark

${ }^{2}$ Department of Cardiology, Aarhus University Hospital, Skejby, Brendstrupgårdsvej 100, Aarhus N DK-8200, Denmark
}

Calcium channel blockers (CCBs) and beta blockers (BBs) are commonly used antihypertensive agents [7]. It has previously been established that elevated preadmission blood pressure is associated with markedly increased stroke mortality [8]. Because the association between blood pressure at hospitalization and mortality is U-shaped in stroke [9], and both ischemic and hemorrhagic strokes are associated with transiently elevated blood pressure in the acute phase [10], we hypothesized that preadmission use of CCBs or BBs could reduce short-term mortality through improved blood pressure control.

It is well established that CCBs and BBs reduce stroke risk in persons with hypertension [11], but it remains 
unknown whether these agents have any effect on mortality following stroke. In a recent study, it was established that angiotensin-converting enzyme inhibitors and angiotensin receptor blockers were associated with reduced 30-day mortality following ischemic stroke but not haemorrhagic stroke [12]. To investigate whether this protective effect extended to other antihypertensive agents, we examined whether use of $\mathrm{CCBs}$ or BBs at time of stroke was associated with reduced short-term mortality.

\section{Methods \\ Setting}

We conducted this nationwide population-based cohort study in Denmark. During the study period (1 July 2004 to 31 December 2012), the total underlying population at risk was 6,379,918 inhabitants. The study period commenced 6 months after establishment of the Danish National Database of Reimbursed Prescriptions (DNDRP) on 1 January 2004, to ensure availability of at least 6 months of preadmission prescription history for all participants [13]. The Danish National Health Service provides universal tax-supported health care, guaranteeing unfettered access to general practitioners and hospitals and partial reimbursement for prescribed medications, including CCBs and BBs [13]. We linked medical registries using the unique central personal registry number assigned to every Danish citizen at birth and to residents upon immigration [14].

\section{Patients with stroke}

In Denmark, care for patients with stroke and other medical emergencies is provided by public hospitals [15]. We used the Danish National Registry of Patients (DNRP), covering all Danish hospitals [16], to identify all patients with a first-time inpatient hospitalization for stroke during the study period. Because more than twothirds of all unspecified strokes (International Classification of Diseases (ICD-10) code: I64) are known to be ischemic strokes (ICD-10 code: I63) [17], we classified unspecified strokes (32\% of all stroke diagnoses [12]) as ischemic strokes. The DNRP contains data on admission and discharge dates and discharge diagnoses from all non-psychiatric hospitals since 1977 and on emergency room and outpatient clinic visits since 1995 [16]. Each hospital discharge is assigned one primary diagnosis and up to 19 secondary diagnoses classified according to the International Classification of Diseases, 8th revision (ICD-8) until the end of 1993 and 10th revision (ICD10) thereafter [16]. We identified patients using both primary and secondary diagnoses for ischemic stroke, $\mathrm{ICH}$, and $\mathrm{SAH}$.

\section{$C C B$ and $B B$ use}

We used the DNDRP to identify all prescriptions redeemed for CCBs and BBs by study participants [13]. Pharmacies in Denmark are equipped with electronic accounting systems, primarily used to secure reimbursement from the National Health Service. For each redeemed prescription, the patient's central personal registry number, the amount and type of drug prescribed according to the Anatomical Therapeutic Chemical (ATC) classification system, and the date the drug was dispensed are transferred electronically from the pharmacies to the DNDRP [13].

We defined current users as patients whose last prescription redemption for CCBs or BBs was $<90$ days before hospital admission for stroke. We chose an exposure window of 90 days to identify most current users, as prescriptions of CCBs/BBs are seldom provided for more than 90 days at a time in Denmark. As the drugs' effects and potential side effects may be less pronounced in longterm users [18], this could lead to underestimation of the association with mortality [18]. Consequently, current users were further categorized into new users, who redeemed their first-ever $\mathrm{CCB}$ or $\mathrm{BB}$ prescription within 90 days before their admission date, and long-term users, who redeemed their first-ever prescription more than 90 days before their admission date. We defined former users as patients whose last prescription redemption was between 90 and 180 days before admission, and non-users as patients with no prescription redemption within 180 days before admission.

\section{Mortality}

We used the Danish Civil Registration System (CRS) to obtain information on all-cause mortality [14]. The CRS has recorded all changes in vital status and migration for the entire Danish population since 1968, with daily electronic updates [14].

\section{Patient characteristics}

The complete inpatient and outpatient medical history available in the DNRP [16] provided information on known prognostic factors (myocardial infarction, atrial fibrillation or flutter, intermittent arterial claudication, diabetes, and dementia) [19] and other potential confounders (Table 1).

To increase the sensitivity of diagnoses of diabetes, COPD, and alcoholism-related diseases, we searched the DNDRP for any previous prescriptions for anti-diabetic medications, respiratory medications, and alcohol deterrents. Relevant ICD and ATC codes are provided in Additional file 1: Table S1.

\section{Comedication use}

We obtained information from the DNDRP on concurrent use (last prescription redemption within 90 days 
Table 1 Characteristics of stroke patients by preadmission use of calcium channel blockers or beta blockers ${ }^{a}$

\begin{tabular}{|c|c|c|c|c|c|c|c|c|c|c|c|c|}
\hline & \multicolumn{4}{|c|}{ Ischemic stroke $(n=83736)$} & \multicolumn{4}{|c|}{ Intracerebral hemorrhage $(n=11779)$} & \multicolumn{4}{|c|}{ Subarachnoid hemorrhage $(n=4528)$} \\
\hline & \multicolumn{2}{|c|}{ Calcium channel blocker } & \multicolumn{2}{|l|}{ Beta blocker } & \multicolumn{2}{|c|}{ Calcium channel blocker } & \multicolumn{2}{|l|}{ Beta blocker } & \multicolumn{2}{|c|}{ Calcium channel blocker } & \multicolumn{2}{|l|}{ Beta blocker } \\
\hline & $\begin{array}{l}\text { Current use } \\
n=13170 \\
(100 \%)\end{array}$ & $\begin{array}{l}\text { Non-use } \\
n=67571 \\
(100 \%)\end{array}$ & $\begin{array}{l}\text { Current use } \\
n=17189 \\
(100 \%)\end{array}$ & $\begin{array}{l}\text { Non-use } \\
n=63402 \\
(100 \%)\end{array}$ & $\begin{array}{l}\text { Current use } \\
n=1163 \\
(100 \%)\end{array}$ & $\begin{array}{l}\text { Non-use } \\
n=10277 \\
(100 \%)\end{array}$ & $\begin{array}{l}\text { Current use } \\
n=1913 \\
(100 \%)\end{array}$ & $\begin{array}{l}\text { Non-use } \\
n=9494 \\
(100 \%)\end{array}$ & $\begin{array}{l}\text { Current use } \\
n=365 \\
(100 \%)\end{array}$ & $\begin{array}{l}\text { Non-use } \\
n=4051 \\
(100 \%)\end{array}$ & $\begin{array}{l}\text { Current use } \\
n=413 \\
(100 \%)\end{array}$ & $\begin{array}{l}\text { Non-use } \\
n=4023 \\
(100 \%)\end{array}$ \\
\hline Male & 47.7 & 52.2 & 46.7 & 52.7 & 51.8 & 51.8 & 51.4 & 51.7 & 44.7 & 42.1 & 46.2 & 42.1 \\
\hline
\end{tabular}

Age, years

$<60$

60-69

70-79

$\geq 80$

\section{Comorbidities}

Cardiovascular diseases

Myocardial infarction $\quad 11.5$

Angina pectoris

Atrial fibrillation or flutter 19.5

Heart valve disease $\quad 6.4$

Intermittent claudication $\quad 5.1$

Venous thromboembolism 4.0

Hypertension

Other diseases

Obesity

Diabetes mellitus

Chronic kidney disease

Chronic pulmonary disease 24.4

Alcoholism-related disease $\quad 4.9$

Dementia

Cancer

Concurrent medications

Cardiovascular drugs

ACE-Is/ARBs

Beta blockers

31.8

Calcium channel blockers

$\begin{array}{llll}20.7 & 9.2 & 21.6 & 12.5 \\ 21.9 & 19.5 & 22.1 & 21.0 \\ 26.2 & 30.7 & 25.9 & 31.8 \\ 31.2 & 40.5 & 30.5 & 34.7\end{array}$

$\begin{array}{llll}26.0 & 11.5 & 27.3 & 24.1 \\ 20.9 & 20.0 & 21.0 & 23.8 \\ 25.2 & 33.3 & 24.0 & 25.5 \\ 27.9 & 35.2 & 27.7 & 26.6\end{array}$

$\begin{array}{lll}57.1 & 24.2 & 57.5 \\ 20.9 & 26.6 & 20.6 \\ 12.6 & 24.2 & 12.4 \\ 9.4 & 24.9 & 9.4\end{array}$

\begin{tabular}{|c|c|c|c|c|c|c|c|c|c|c|}
\hline 7.9 & 18.6 & 5.3 & 9.8 & 5.6 & 16.6 & 3.8 & 5.2 & 2.8 & 15.7 & 1.6 \\
\hline 8.2 & 21.6 & 4.8 & 11.6 & 5.3 & 17.8 & 3.3 & 7.1 & 2.7 & 18.2 & 1.4 \\
\hline 13.4 & 33.1 & 10.0 & 25.1 & 10.1 & 30.4 & 7.5 & 21.1 & 5.7 & 32.4 & 4.1 \\
\hline 12.1 & 30.3 & 8.5 & 23.6 & 11.8 & 38.2 & 7.5 & 15.1 & 4.3 & 24.7 & 2.9 \\
\hline 4.0 & 8.6 & 3.2 & 6.7 & 3.7 & 11.0 & 2.6 & 4.7 & 1.6 & 6.8 & 1.3 \\
\hline 2.6 & 4.9 & 2.5 & 4.0 & 1.5 & 3.6 & 1.4 & 2.7 & 1.0 & 2.7 & 1.0 \\
\hline 3.7 & 4.2 & 3.6 & 4.6 & 3.3 & 4.7 & 3.2 & 2.5 & 2.0 & 3.9 & 1.8 \\
\hline 19.3 & 47.4 & 18.4 & 55.3 & 18.8 & 52.1 & 16.7 & 47.9 & 10.5 & 46.0 & 10.3 \\
\hline 3.6 & 5.4 & 3.5 & 7.4 & 2.7 & 6.2 & 2.5 & 5.2 & 2.9 & 5.8 & 2.7 \\
\hline 11.7 & 19.4 & 11.5 & 19.1 & 8.2 & 18.3 & 7.5 & 14.2 & 4.8 & 13.3 & 4.6 \\
\hline 2.1 & 5.0 & 1.8 & 8.5 & 2.0 & 7.0 & 1.8 & 6.0 & 1.0 & 5.8 & 1.1 \\
\hline 19.9 & 21.5 & 20.5 & 23.7 & 18.3 & 20.6 & 18.5 & 28.8 & 16.8 & 24.2 & 17.3 \\
\hline 6.8 & 5.2 & 6.8 & 5.8 & 8.4 & 6.2 & 8.4 & 5.5 & 7.6 & 10.4 & 7.1 \\
\hline 3.3 & 3.2 & 3.4 & 4.6 & 3.9 & 3.6 & 4.0 & 2.2 & 1.2 & 2.2 & 1.3 \\
\hline 14.0 & 16.2 & 13.9 & 18.7 & 15.3 & 18.6 & 15.0 & 16.4 & 8.0 & 18.2 & 7.8 \\
\hline
\end{tabular}


Table 1 Characteristics of stroke patients by preadmission use of calcium channel blockers or beta blockers ${ }^{\mathrm{a}}$ (Continued)

\begin{tabular}{|c|c|c|c|c|c|c|c|c|c|c|c|c|}
\hline Diuretics & 44.4 & 24.2 & 48.8 & 21.8 & 40.3 & 19.0 & 43.7 & 16.5 & 32.6 & 11.0 & 39.5 & 9.9 \\
\hline Nitrates & 4.3 & 1.4 & 5.2 & 1.0 & 3.9 & 1.0 & 3.9 & 0.6 & 2.5 & 0.4 & 3.9 & 0.1 \\
\hline Statins & 28.1 & 13.7 & 31.9 & 11.7 & 30.8 & 11.9 & 31.4 & 10.3 & 25.8 & 8.5 & 33.9 & 7.5 \\
\hline Aspirin & 38.9 & 21.1 & 45.8 & 18.2 & 37.7 & 18.9 & 42.1 & 16.5 & 29.6 & 8.2 & 35.1 & 7.2 \\
\hline Clopidogrel & 3.1 & 1.6 & 4.7 & 1.1 & 3.1 & 1.3 & 4.6 & 0.9 & 1.9 & 0.9 & 4.8 & 0.5 \\
\hline Vitamin $\mathrm{K}$ antagonists & 7.7 & 4.1 & 10.9 & 2.9 & 19.1 & 8.9 & 29.0 & 5.9 & 8.5 & 2.9 & 16.2 & 1.9 \\
\hline \multicolumn{13}{|l|}{ Other drugs } \\
\hline Systemic glucocorticoids & 5.8 & 4.6 & 5.2 & 4.7 & 4.8 & 3.8 & 5.2 & 3.7 & 6.3 & 2.4 & 3.9 & 2.6 \\
\hline SSRIS & 10.6 & 8.7 & 10.1 & 8.7 & 11.2 & 9.5 & 12.7 & 9.2 & 9.3 & 6.9 & 11.9 & 6.5 \\
\hline Bisphosphonates & 4.0 & 3.3 & 4.0 & 3.3 & 4.1 & 3.7 & 4.5 & 3.6 & 5.2 & 2.3 & 3.9 & 2.2 \\
\hline NSAIDs & 12.1 & 10.7 & 11.2 & 10.9 & 11.4 & 10.2 & 9.4 & 10.6 & 15.1 & 10.4 & 11.4 & 10.8 \\
\hline
\end{tabular}

${ }_{\mathrm{a}} \mathrm{n}=100,043$. Table values are given as \%. Data for former users are not shown $(\mathrm{n}=2995 / 3145$ among ischemic stroke patients, 339/372 among intracerebral hemorrhage patients, and 112/92 among subarachnoi hemorrhage patients for calcium channel blockers/beta blockers, respectively). ACE-Is/ARBs indicates angiotensin converting enzyme inhibitors/angiotensin receptor blockers; SSRls, selective serotonin reuptake inhibitors;

NSAIDs, nonsteroidal anti-inflammatory drugs. 
before admission) of other drugs that may potentially affect stroke prognosis [13]. Relevant ATC codes are provided in Additional file 1: Table S1.

\section{Statistical analysis}

We characterized the stroke cohort according to sex, age group ( $<60,60-69,70-79, \geq 80$ years), individual comorbidities, and comedication use. We followed all patients from hospital admission date until death, emigration, or 30 days of follow up, whichever came first.

We used a Cox proportional-hazards regression analysis to compute the hazard ratio as a measure of the mortality rate ratio (MRR) within 30 days of hospital admission for current, new, long-term, and former use compared with non-use. The analysis was adjusted for sex, age groups, and the individual comorbidities and comedications listed in Table 1. The proportional hazard assumption was assessed using log-log plots and found valid. We repeated the analysis stratifying by sex, age group, and presence/absence of myocardial infarction, congestive heart failure, atrial fibrillation or flutter, angina pectoris, hypertension, diabetes, and chronic kidney disease.

We performed four sensitivity analyses. First, to increase the positive predictive value (PPV) of the stroke diagnosis, we restricted the analyses to patients who had a computed tomography (CT) or magnetic resonance imaging (MRI) scan registered in the DNRP during the stroke admission. Second, to examine the sensitivity of the estimates to differences in exposure definitions, we repeated the analysis substituting 60-day and 30-day exposure windows for the 90-day exposure window. Third, to reduce the potential for confounding by indication for $\mathrm{CCB}$ and $\mathrm{BB}$ use, we directly compared current users with former users. Fourth, we repeated the analysis separating ischemic stroke into "unspecified stroke" and "specified ischemic stroke". Analyses were performed using SAS version 9.2 (SAS Institute Inc., Cary, NC, USA). The study was approved by the Danish Data Protection Agency (record number 2011-41-5755). As this study did not involve contact with patients or any intervention, it was not required to obtain permission from the Danish Scientific Ethical Committee or to obtain patient consents.

\section{Results}

\section{Patient characteristics}

Patient characteristics are shown in Table 1. We identified 100,043 patients with a first-time stroke. Of these, 83,736 (83.7\%) patients had ischemic stroke (median age: 74 years), 11,779 (11.8\%) had ICH (median age: 72 years), and 4,528 (4.5\%) had SAH (median age: 58 years). A total of 14,698 patients $(14.7 \%)$ were current CCBs users, 3,446 (3.4\%) were former users, and 81,899 $(81.9 \%)$ were non-users. For BBs, the distribution was similar with a total of 19,515 (19.5\%) current users, 3,609 (3.6\%) former users, and 76,919 (76.9\%) non-users. All cardiovascular diseases, obesity, diabetes mellitus, chronic kidney disease, and use of all cardiovascular drugs were more common among current users of $\mathrm{CCB}$ and $\mathrm{BB}$ in each stroke group than among non-users. Median age was also higher among current $\mathrm{CCB} / \mathrm{BB}$ users than among non-users.

\section{Mortality}

Overall 30-day mortality risk among non-users of $\mathrm{CCB}$ or BB was $10 \%$ for ischemic stroke, $33-34 \%$ for $\mathrm{ICH}$, and $23 \%$ for SAH (Table 2). After multivariable adjustment, current use of CCBs or BBs was not associated with mortality compared with non-use for ischemic stroke [30-day MRR $=0.99$ (95\% confidence interval (CI): 0.941.05) for $\mathrm{CCB}$ and 1.01 (95\% CI: 0.96-1.07) for $\mathrm{BB}]$, for ICH [30-day MRR $=1.05$ (95\% CI: 0.95-1.16) for CCB and 0.95 (95\% CI: 0.87-1.04) for BB], or for SAH [30-day $\mathrm{MRR}=1.05$ (95\% CI: 0.85-1.29) for CCBs and 0.89 (95\% CI: 0.72-1.11) for BBs]. No association with mortality was found for former use of CCBs or BBs compared with non-use (Table 2).

We found no substantial modification of the CCB or $\mathrm{BB}$ association (Additional file 1: Table S7). However, among ICH patients we found a reduction in MRR in younger users of both CCB (age <60 years) and BB (age between 60-69 years) although CIs were partly overlapping between age groups.

The results were robust in the analysis restricted to CT- or MRI-confirmed diagnoses (Additional file 1: Table S2) and in analyses using a 60-day (Additional file 1: Table S3) and 30-day (Additional file 1: Table S4) exposure window. Also, when current users were compared directly with former users (Additional file 1: Table S5) and when "unspecified stroke" and "specified ischemic stroke" were analyzed separately (Additional file 1: Table S6), no association with mortality following ischemic stroke, ICH, or SAH was found.

\section{Discussion}

In this cohort study with virtually complete follow-up of 100,043 patients hospitalized for stroke, preadmission use of CCBs or BBs was not associated with 30-day mortality following ischemic stroke, ICH, or SAH. The results may be generalized to most industrial Western societies where changes in risk factor modification and treatment have followed international recommendations.

A number of studies have examined use of CCBs or BBs after stroke onset. A meta-analysis of 34 randomized controlled trials encompassing a total of 7,731 patients evaluated CCB administration versus control (placebo or standard medical treatment alone) after ischemic stroke onset and reported no beneficial effect on 
Table 2 Preadmission use of calcium channel blockers or beta blockers and 30-day mortality estimates following stroke

\begin{tabular}{|c|c|c|c|c|c|c|}
\hline & \multicolumn{3}{|c|}{ Calcium channel blocker } & \multicolumn{3}{|l|}{ Beta blocker } \\
\hline & \multirow{2}{*}{$\begin{array}{l}\text { Mortality risk, } \\
\%(95 \% \mathrm{Cl})\end{array}$} & \multicolumn{2}{|c|}{ Mortality rate ratio $(95 \% \mathrm{Cl})$} & \multirow{2}{*}{$\begin{array}{l}\text { Mortality risk, } \\
\%(95 \% \mathrm{Cl})\end{array}$} & \multicolumn{2}{|c|}{ Mortality rate ratio $(95 \% \mathrm{Cl})$} \\
\hline & & Unadjusted & Adjusted $^{\mathrm{a}}$ & & Unadjusted & Adjusted $^{\mathrm{a}}$ \\
\hline \multicolumn{7}{|l|}{ Ischemic stroke } \\
\hline Non-use & $10.3(10.1-10.5)$ & 1 (reference) & 1 (reference) & $9.8(9.5-10.0)$ & 1 (reference) & 1 (reference) \\
\hline Former use & $13.1(11.9-14.3)$ & $1.29(1.16-1.43)$ & $1.04(0.94-1.15)$ & $13.0(11.8-14.2)$ & $1.35(1.22-1.49)$ & $1.01(0.91-1.12)$ \\
\hline Current use & $12.4(11.9-13.0)$ & $1.22(1.15-1.29)$ & $0.99(0.94-1.05)$ & $13.9(13.3-14.4)$ & $1.45(1.38-1.52)$ & $1.01(0.96-1.07)$ \\
\hline New use & $10.1(9.1-11.1)$ & $0.97(0.88-1.08)$ & $0.89(0.80-0.99)$ & $12.6(11.6-13.6)$ & $1.31(1.19-1.43)$ & $0.97(0.88-1.06)$ \\
\hline Long-term use & $13.3(12.6-14.0)$ & $1.31(1.24-1.39)$ & $1.03(0.97-1.10)$ & $14.3(13.7-14.9)$ & $1.50(1.42-1.58)$ & $1.02(0.96-1.08)$ \\
\hline \multicolumn{7}{|c|}{ Intracerebral hemorrhage } \\
\hline Non-use & $34.1(33.2-35.0)$ & 1 (reference) & 1 (reference) & $33.3(32.4-34.3)$ & 1 (reference) & 1 (reference) \\
\hline Former use & $37.5(32.6-42.9)$ & $1.11(0.93-1.32)$ & $0.92(0.77-1.10)$ & $40.6(35.8-45.8)$ & $1.29(1.09-1.52)$ & $1.00(0.84-1.19)$ \\
\hline Current use & $41.3(38.6-44.2)$ & $1.28(1.16-1.41)$ & $1.05(0.95-1.16)$ & $41.9(39.7-44.2)$ & $1.35(1.25-1.46)$ & $0.95(0.87-1.04)$ \\
\hline New use & $36.6(31.4-42.5)$ & $1.09(0.90-1.33)$ & $0.95(0.78-1.16)$ & $41.7(37.2-46.6)$ & $1.36(1.17-1.58)$ & $0.96(0.81-1.12)$ \\
\hline Long-term use & $42.9(39.7-46.3)$ & $1.35(1.21-1.50)$ & $1.09(0.97-1.22)$ & $42.0(39.5-44.5)$ & $1.35(1.24-1.47)$ & $0.94(0.85-1.04)$ \\
\hline \multicolumn{7}{|c|}{ Subarachnoid hemorrhage } \\
\hline Non-use & $22.6(21.3-23.9)$ & 1 (reference) & 1 (reference) & $22.8(21.6-24.2)$ & 1 (reference) & 1 (reference) \\
\hline Former use & $32.2(24.4-41.7)$ & $1.51(1.08-2.11)$ & $1.05(0.75-1.48)$ & $25.0(17.4-35.2)$ & $1.12(0.74-1.69)$ & $0.60(0.38-0.95)$ \\
\hline Current use & $33.0(28.4-38.0)$ & $1.56(1.29-1.89)$ & $1.05(0.85-1.29)$ & $31.6(27.3-36.3)$ & $1.46(1.21-1.75)$ & $0.89(0.72-1.11)$ \\
\hline New use & $29.1(21.0-39.5)$ & $1.38(0.94-2.02)$ & $0.98(0.66-1.45)$ & $28.3(20.5-38.3)$ & $1.24(0.85-1.81)$ & $0.70(0.46-1.06)$ \\
\hline Long-term use & $34.3(28.9-40.2)$ & $1.62(1.31-2.01)$ & $1.06(0.84-1.34)$ & $32.6(27.7-38.1)$ & $1.53(1.25-1.88)$ & $0.92(0.72-1.17)$ \\
\hline
\end{tabular}

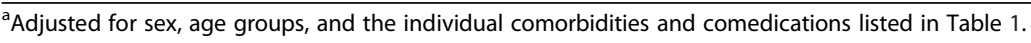

mortality (risk ratio $=1.07,95 \%$ CI: 0.98-1.17) [20]. CCBs are prescribed as a component of vasospasm management after $\mathrm{SAH}$ onset and another recent meta-analysis reports more than $50 \%$ mortality reduction in $\mathrm{SAH}$ patients receiving this treatment $(\mathrm{OR}=0.45,95 \% \mathrm{CI}$ : 0.15 1.29) [21]. As we studied the prognostic effect of CCB or $\mathrm{BB}$ use initiated before and not after hospitalization for stroke, our neutral results do not necessarily contradict these findings.

The effect of BB use before ischemic stroke on subsequent stroke severity has been examined in two cohort studies of 111 [22] and 1,375 [23] patients. Both studies reported a beneficial effect on stroke severity as measured by the Canadian Neurologic Scale, the National Institute of Health Stroke Scale [24], or the European Stroke Scale [25]. Although both studies examined pre-stroke use of $\mathrm{BB}$, neither included mortality as an outcome measure. Consequently our results are not directly comparable.

It has recently been established that preadmission use of angiotensin-converting enzyme inhibitors and angiotensin receptor blockers reduces the 30-day mortality following ischemic stroke, whereas there was no association for $\mathrm{ICH}$ and $\mathrm{SAH}$ [12]. Our null results for ischemic stroke suggest that the positive effect of angiotensin-converting enzyme inhibitors and angiotensin receptor blockers on ischemic stroke mortality is mediated via pathways other than blood pressure control.

Transient hypertension is a common finding in the acute phase of stroke, and its management has been subject of debate [26]. A recent randomized trial of 4,071 patients, which examined the effect of blood pressure reduction in the acute phase of ischemic stroke, reported no difference between treatment groups on mortality up to 14 days or on major disability $(\mathrm{OR}=1.00,95 \% \mathrm{CI}$ : 0.88-1.14) [27]. Our study supports a neutral effect of antihypertensive drug use on mortality following stroke, although we examined $\mathrm{CBB}$ and $\mathrm{BB}$ use initiated prior to stroke onset.

The rise in blood pressure during acute stroke was investigated in a recent population-based study of 653 patients with acute ischemic stroke or ICH [10]. Systolic blood pressure was substantially elevated compared with usual pre-stroke levels after intracerebral hemorrhage, whereas acute-phase systolic blood pressure after major ischemic stroke was only marginally raised. This suggests that the benefits of lowering blood pressure acutely after stroke might be expected to differ, favoring $\mathrm{ICH}$ [10]. Consistent with this interpretation, our results do not exclude a protective effect of preadmission use of $\mathrm{CCB}$ or $\mathrm{BB}$ among patients experiencing $\mathrm{ICH}$ at younger 
ages, although CIs were overlapping between strata of age (Additional file 1: Table S7).

A major strength of our study was its large size, providing statistically precise estimates. The study's populationbased design in the setting of a tax-supported universal healthcare system with unfettered access and complete follow-up of all patients largely eliminated selection bias. As well, the complete and prospectively recorded hospital and prescription histories reduced the risk of information biases [28].

A potential limitation is that our stroke data were derived from routine hospital discharge diagnoses, which may introduce coding errors [17]. The positive predictive value of acute stroke diagnoses in the DNRP has previously been validated and found to be approximately $97 \%$ for ischemic stroke, $74 \%$ for $\mathrm{ICH}$, and $67 \%$ for SAH [17]. Misclassification due to coding errors would most likely be non-differential and thus could explain at least part of the neutral results in this study. However, in sensitivity analyses restricted to CT or MRI-confirmed cases, the results remained robust.

Because we classified unspecified strokes as ischemic strokes, a few ICHs (approximately 6\%) were inevitably misclassified as ischemic strokes [17]. As we found no overall association between $\mathrm{CBB}$ or $\mathrm{BB}$ use and $\mathrm{ICH}$ mortality, such misclassification would bias the results for ischemic stroke towards the null.

Data on reimbursed medications are virtually complete in the prescription database [13], and neither $\mathrm{CCB}$ nor BB are sold over-the-counter in Denmark. We therefore identified all patients with redeemed prescriptions for $\mathrm{CBB}$ and $\mathrm{BB}$. Still, use of redeemed prescriptions as a proxy for actual drug use may not always be accurate. We did base drug exposure information on actual dispensing at pharmacies rather than just on written prescriptions [13]. Mortality data, as recorded in the CRS, are virtually complete [14].

Although we controlled for several potential confounding factors, we cannot exclude unmeasured confounding. Moreover, we lacked information on smoking and blood pressure levels. However, we did adjust for hospital diagnoses of COPD and hypertension as proxy measures. Smoking and hypertension may worsen prognosis after stroke and are likely more prevalent among $\mathrm{CCB}$ and $\mathrm{BB}$ users than among non-users. Thus, such potential confounding would have biased our estimates towards increased mortality among CCB and BB users.

Although we adjusted for diagnoses of obesity, hospitalbased registration is likely to be incomplete and residual confounding may persist. We lacked accurate information on Body Mass Index, which is a major limitation for adequately adjusting for obesity. However, we expect potential residual confounding to have negligible impact on the results.

\section{Conclusions}

Preadmission use of CCBs or BBs was not associated with overall 30-day mortality among patients with ischemic stroke, ICH, or SAH.

\section{Additional file}

Additional file 1: Supplemental online tables.

\section{Competing interests}

The authors declare that they have no competing interests.

\section{Authors' contributions}

MS and HTS conceived the study idea and designed the study. HTS and LP collected the data. JS, MS, and HTS reviewed the literature. MS directed the analyses, which were performed by EHP. JS, MS, EHP, CFC, LP, HEB, and HTS participated in the discussion and interpretation of the results. JS organized the writing and wrote the initial draft. JS, MS, EHP, CFC, LP, HEB, and HTS critically revised the manuscript for intellectual content and approved the final version before submission. HTS had full access to all data used in the study and takes responsibility for the integrity of the data and the accuracy of the data analysis. All authors read and approved the final manuscript.

\section{Acknowledgements}

The study was supported by the Clinical Epidemiology Research Foundation and the Aarhus University Research Foundation. Neither funding source had a role in the design, conduct, analysis, or reporting of the study.

Received: 22 September 2014 Accepted: 20 February 2015

Published online: 07 March 2015

\section{References}

1. Mukherjee D, Patil CG. Epidemiology and the global burden of stroke. World Neurosurg. 2011;76:S85-90.

2. Truelsen T, Piechowski-Jozwiak B, Bonita R, Mathers C, Bogousslavsky J, Boysen G. Stroke incidence and prevalence in Europe: a review of available data. Eur J Neurol. 2006;13:581-98.

3. Lozano R, Naghavi M, Foreman K, Lim S, Shibuya K, Aboyans V, et al. Global and regional mortality from 235 causes of death for 20 age groups in 1990 and 2010: a systematic analysis for the global burden of disease study 2010. Lancet. 2012;380:2095-128.

4. Go AS, Mozaffarian D, Roger VL, Benjamin EJ, Berry JD, Borden WB, et al. Heart disease and stroke statistics-2013 update: a report from the American Heart Association. Circulation. 2013;127:e6-245.

5. Schmidt M, Jacobsen JB, Johnsen SP, Bøtker HE, Sørensen HT. Eighteen-year trends in stroke mortality and the prognostic influence of comorbidity. Neurology. 2014:82:340-50.

6. González-Pérez A, Gaist D, Wallander MA, McFeat G, García-Rodriguez LA. Mortality after hemorrhagic stroke: data from general practice (The Health Improvement Network). Neurology. 2013;81:559-65.

7. Mancia G, Fagard R, Narkiewicz K, Redon J, Zanchetti A, Bohm M, et al. ESH/ ESC guidelines for the management of arterial hypertension: the task force for the management of arterial hypertension of the european society of hypertension (ESH) and of the european society of cardiology (ESC). Eur Heart J. 2013;2013(34):2159-219.

8. Lewington S, Clarke R, Qizilbash N, Peto R, Collins R. Age-specific relevance of usual blood pressure to vascular mortality: a meta-analysis of individual data for one million adults in 61 prospective studies. Lancet. 2002;360:1903-13.

9. Vemmos KN, Tsivgoulis G, Spengos K, Zakopoulos N, Synetos A, Manios E, et al. U-shaped relationship between mortality and admission blood pressure in patients with acute stroke. J Intern Med. 2004;255:257-65.

10. Fischer U, Cooney MT, Bull LM, Silver LE, Chalmers J, Anderson CS, et al. Acute post-stroke blood pressure relative to premorbid levels in intracerebral haemorrhage versus major ischaemic stroke: a population-based study. Lancet Neurol. 2014;13:374-84

11. Rothwell PM, Howard SC, Dolan E, O'Brien E, Dobson JE, Dahlof B, et al. Effects of beta blockers and calcium-channel blockers on within-individual variability in blood pressure and risk of stroke. Lancet Neurol. 2010;9:469-80. 
12. Sundbø\|l J, Schmidt M, Horváth-Puhó E, Christiansen C, Pedersen L, Bøtker $H E$, et al. Preadmission use of ACE inhibitors or angiotensin receptor blockers and short-term mortality after stroke. J Neurol Neurosurg Psychiatry. 2014. in press.

13. Johannesdottir SA, Horváth-Puhó E, Ehrenstein V, Schmidt M, Pedersen L, Sørensen HT. Existing data sources for clinical epidemiology: the Danish national database of reimbursed prescriptions. Clin Epidemiol. 2012;4:303-13.

14. Schmidt M, Pedersen L, Sørensen HT. The Danish civil registration system as a tool in epidemiology. Eur J Epidemiol. 2014;29:541-9.

15. Thorvaldsen P, Davidsen M, Brønnum-Hansen H, Schroll M. Stable stroke occurrence despite incidence reduction in an aging population : stroke trends in the Danish monitoring trends and determinants in cardiovascular disease (MONICA) population. Stroke. 1999;30:2529-34.

16. Andersen TF, Madsen M, Jorgensen J, Mellemkjoer L, Olsen JH. The Danish national hospital register. A valuable source of data for modern health sciences. Dan Med Bull. 1999;46:263-8.

17. Krarup LH, Boysen $G$, Janjua $H$, Prescott E, Truelsen T. Validity of stroke diagnoses in a National Register of Patients. Neuroepidemiology. 2007; $28: 150-4$

18. Ray WA. Evaluating medication effects outside of clinical trials: New-user designs. Am J Epidemiol. 2003;158:915-20.

19. Andersen KK, Andersen ZJ, Olsen TS. Predictors of early and late case-fatality in a nationwide Danish study of 26,818 patients with first-ever ischemic stroke. Stroke. 2011:42:2806-12.

20. Zhang J, Yang J, Zhang C, Jiang X, Zhou H, Liu M. Calcium antagonists for acute ischemic stroke. Cochrane Database Syst Rev. 2012;5:CD001928.

21. Huang $R Q$, Jiang FG, Feng ZM, Wang TY. Nicardipine in the treatment of aneurysmal subarachnoid haemorrhage: a meta-analysis of published data. Acta Neurol Belg. 2013;113:3-6.

22. Laowattana S, Oppenheimer SM. Protective effects of beta-blockers in cerebrovascular disease. Neurology. 2007;68:509-14.

23. De Raedt S, Haentjens P, De Smedt A, Brouns R, Uyttenboogaart M, LuijckX $\mathrm{GJ}$, et al. Pre-stroke use of beta-blockers does not affect ischemic stroke severity and outcome. Eur J Neurol. 2011;19:234-40.

24. Muir KW, Weir CJ, Murray GD, Povey C, Lees KR. Comparison of neurological scales and scoring systems for acute stroke prognosis. Stroke. 1996;27:1817-20.

25. Hantson L, De Weerdt W, De Keyser J, Diener HC, Franke C, Palm R, et al. The European Stroke Scale. Stroke. 1994;25:2215-9.

26. Hubert GJ, Müller-Barna P, Haberl RL. Unsolved Issues in the Management of High Blood Pressure in Acute Ischemic Stroke. Int J Hypertens. 2013;2013:1-5

27. He J, Zhang $Y, X u T$, Zhao $Q$, Wang $D$, Chen CS, et al. Effects of immediate blood pressure reduction on death and major disability in patients with acute ischemic stroke: the CATIS randomized clinical trial. JAMA. 2014;311:479-89.

28. Sørensen HT. Regional administrative health registries as a resource in clinical epidemiologyA study of options, strengths, limitations and data quality provided with examples of use. Int J Risk Saf Med. 1997;10:1-22.

\section{Submit your next manuscript to BioMed Central and take full advantage of:}

- Convenient online submission

- Thorough peer review

- No space constraints or color figure charges

- Immediate publication on acceptance

- Inclusion in PubMed, CAS, Scopus and Google Scholar

- Research which is freely available for redistribution 